\title{
Microstructure and High Temperature Oxidation Behavior of Aluminum Alloyed Cast Irons
}

\author{
Mohammed Jasim Kadhim \\ Department of Production Engineering and Metallurgy \\ University of Technology, Baghdad, Iraq \\ Tel: 964-790-549-9306 E-mail: alimohammed1957@yahoo.com \\ Adnan Naama Abood \\ Technical College, Baghdad, Iraq \\ Tel: 964-770-533-4938 E-mail: adnan_naama@yahoo.com \\ Hijran Zainalabidin \\ Department of Production Engineering and Metallurgy \\ University of Technology, Baghdad, Iraq \\ Tel: 964-790-320-7729 E-mail: hijzain@yahoo.com
}

\begin{abstract}
The present study postulates the phases formed/oxidation resistance of aluminum alloyed cast irons ( 0 to $4 \mathrm{wt} \%$ Al) based on scanning electron microscopy, energy dispersive X-ray spectroscopy (EDS), X-ray diffraction and oxidation test. Mechanisms of the oxidation of the alloys were determined at high temperatures $\left(700-1000{ }^{\circ} \mathrm{C}\right)$. A direct relationship between $\mathrm{Al}$ content and oxidation temperature was found; at a lower oxidation temperature (less than $800{ }^{\circ} \mathrm{C}$ ), low oxidation resistances were obtained characterized by formation of $\mathrm{FeO}, \mathrm{Fe}_{3} \mathrm{O}_{4}$ and $\mathrm{Fe}_{2} \mathrm{O}_{3}$. With increasing the $\mathrm{Al}$ content, the performance of the alloys enhanced noticeably. Scale thickness was reduced progressively with increasing aluminum content. Under all testing conditions, the oxidation kinetics is parabolic with different parabolic rate constants.
\end{abstract}

Keywords: Aluminum alloyed cast irons, Oxidation resistance, Phases, Oxidation kinetics

\section{Introduction}

Prolonged services at elevated temperature require combination of properties that would be difficult to achieve without addition of special alloying elements. The addition of suitable alloying elements to cast irons is the most important way to protect them against high temperature oxidation and scaling (Li, Perrin, Burger, McFarlan, Black, Logan and Williams, 2004). When the protective scale are adherent and non porous, the oxidation process will be inhibited and progressive process of oxidation will be prevented. Many elements, such as $\mathrm{Si}, \mathrm{Cr}$, and $\mathrm{Al}$ provide this protective layer for alloyed cast irons (Pint, Tortorelli, and Wright, 1999; Xu, Ferry, and Wang, 2005).

Cast irons containing aluminum show excellent oxidation resistance by causing the formation of an adherent aluminum-rich oxide films. Cast irons alloyed with aluminum form a thin, tightly adhering oxide film on the surface that inhibits further oxygen diffusion into the substrate. Due to similar graphitization effect of aluminum and silicon, in some types of alloyed cast irons, aluminum replaces much of silicon that is normally present in cast irons. In other types of cast irons, aluminum is added as an alloying element in addition to the normal silicon content (Smickley and Rundman., 1981). The elevated temperature properties of the aluminum cast irons are enhanced appreciably by the addition of one to two percent of molybdenum. Combination of high silicon plus aluminum and molybdenum produces ductile cast irons with excellent qualification for high temperature applications (Rana, Khan, Amjad, and Abbas, 2001).

Hardwick and Wallwork (1978) illustrated that sufficient quantities of chromium, aluminum, or silicon must be presented in an alloy to ensure that protective oxide $\left(\mathrm{CrO}_{2}, \mathrm{Al}_{2} \mathrm{O}_{3}, \mathrm{SiO}_{2}\right)$ are formed on exposure to oxidizing environments. Aluminum scales appear very attractive, particularly at high temperatures due to reducing cations diffusion through scale and its high free energy formed (greater than that of $\mathrm{CrO}_{2}$ ). Aluminum-forming cast iron alloys are good candidates to resist high temperature oxidation atmospheres because alumina scales, especially $\alpha-\mathrm{Al}_{2} \mathrm{O}_{3}$, exhibits excellent resistance; these scales acting as diffusion barriers during the oxidation process at 
high temperatures (Chevalier1, Houngninou1, Paris, Bernard1, Gaffet, Munir,, Larpin and Borchardt, 2003). The industrial boiler casting produced from cast irons containing 5-7\% aluminum, with $0.7-1.0 \% \mathrm{C}$, exhibits $6-8$ times longer life than the medium silicon heat resistant ductile cast irons at operating temperature of about 1000 ${ }^{\circ} \mathrm{C}$ (Sun, and Wang, 1996). (Kiani Rashid and Edmonds, 2003) found that in cast irons containing aluminum a very thin and adherent film of aluminum oxide is produced at the short period of heating. It protects the bulk of the alloy from the further attack and the average thickness of iron-rich oxide layers decrease as the aluminum content increases. The present study is mainly concentrates on the effect of aluminum content on the phases formed and the oxidation resistance relationship.

\section{Experimental Procedure}

Three cast iron alloys contain different amount of aluminium were produced using silica lined coreless induction furnace. The liquid alloys were poured at temperatures between 1350 and $1400{ }^{\circ} \mathrm{C}$ in a sand mold to produce $200 \mathrm{~mm}$ long x $25 \mathrm{~mm}$ diameter test bars. The chemical composition of the alloys studied is listed in Table 1 .

For Oxidation tests, circular shape specimens with dimensions of $20 \mathrm{~mm}$ diameter x $4.5 \mathrm{~mm}$ thick were sectioned from test bars (ASTM G54-84, 1988) (Nicholls and Bennett, 2000). They were degreased with acetone and ultrasonically cleaned. Microbalance with accuracy $\pm 0.1 \mathrm{mg}$ was used to determine the weight gain. Oxide surfaces were examined using optical microscopy (OM) and scanning electron microscopy (SEM). High temperature isothermal oxidation experiments were carried out in a muffle furnace in static air. The specimens were oxidized at temperatures of $700,800,900$, and $1000{ }^{\circ} \mathrm{C}$ at interval time up to $100 \mathrm{hrs}$. The specimens were weighed periodically, every $5 \mathrm{hrs}$. X- ray diffraction was carried out to determine the phases formed in Al-free cast iron and aluminum alloyed cast irons before and after oxidation tests.

\section{Results and Discussion}

The microstructural analysis using optical microscopy, scanning electron microscopy (SEM) equipped with energy dispersive spectrometer (EDS) and X-ray diffraction (XRD) of as cast irons with different content of aluminum show indication of different phases formed. Some of these analyses are shown in Fig. 1. Different shapes, sizes and distribution of structural elements were found. Structural effects were dominated by a significant increase in percent of ferrite at high level of aluminum content. The different phases found were mainly $\boldsymbol{\alpha}$-iron, graphite and pearlite . Analysis of cast iron with 2.7 and $4.0 \%$ aluminum indicate that ferrite is the main matrix component with graphite in the flake shape. Graphite morphology and its distribution were different from non-alloyed cast iron. Evidence of existing of more volume fraction of pearlite as aluminum percent was increased. Different hardness levels can be related to the variation in their microstructure; it shows the dependence of hardness on aluminum content. Matrix free from carbide formed in alloys contain aluminum content up to $4.0 \%$ shows a relatively low hardness $(220-360 \mathrm{HV})$; this is a result of the predominant ferrite phase with identification of different amounts of pearlite.

It was found that the first stage of oxidation normally starts by the oxidation of graphite flakes exposed to oxidizing air environment, then followed by oxidation of exposed alloying elements. In this period, if weight change is directed to a negative weight loss. This could be due to the high rate of carbon oxidation compared to metal oxidation. In the followed stage of oxidation, normally the weight gain by formation iron oxide scales prevails over the weight loss by decarburization. The oxidation kinetics observed for alloy I without $\mathrm{Al}$ can be ascribed to the combined effects of iron oxide accumulation (weight gain); the weight losses were due to the decarburization (Fig. 2). When the consumption of graphite at the surface exceeds the relative weight gain due to oxidation of iron, the weight change tends to be negative. While in the exceeding of weight gain due to oxide formation more than decarburization, the total weight change starts increasing. It is believed that cavities or gaps are left after graphite consumption, but iron oxides could fill these holes and thereby provide anchors that could key the scale to the metal. The scale cracking and spallation or partial spallation can cause the fluctuation in the weight change rate.

The existence of cracks in the oxide layer caused a rapid increase in the surface area in contact with oxygen and then accelerates the oxidation kinetics (Fig. 3). It was noted that after the first stage of oxidation period at 900 and $1000{ }^{\circ} \mathrm{C}$ the scale formed on the alloy I tends to spall from the surface on cooling. When the scale spalled away, the surface oxidized again and scale appears more adherent to the subsurface. The scale formed on oxidized cast iron at high temperatures is composed of different layers consist of different types of iron oxides; $\mathrm{FeO}, \mathrm{Fe}_{3} \mathrm{O}_{4}$ and $\mathrm{Fe}_{2} \mathrm{O}_{3}$.

Figures 4 and 5 show that oxide layers formed on the surface of alloys II and III (2.7 and 4\% Al) are expected to exert a favorable influence on the retardation of the oxidation. The oxidation of low aluminum cast irons were controlled by outward diffusion of iron ions in the scale and that the oxidation rates decrease with increasing 
aluminum content. The solubility of aluminum in iron oxides leads to a change in the characteristics of the oxide and hence to the retardation of diffusion of iron ions. As in other alloyed cast iron, external protective scales are formed initially; these scales suffer cracking and spalling within a short period. Subsequently, a second or a third scale were observed which affects the oxidation rate (Fig. 6). Small particles are released from the specimens; this gives an evidence of oxide behavior of the alloy.

The oxidation processes followed parabolic rate law. The parabolic rate constant $\left(\mathrm{k}_{\mathrm{p}}\right)$ for alloy II and alloy III, have the same tendency to increase the oxidation rate with temperature. The parabolic rate constants for 2.7 and $4.0 \%$ aluminum alloys at $700{ }^{\circ} \mathrm{C}$ are $1.43 \times 10^{-10}$ and $1.04 \times 10^{-10} \mathrm{~g}^{2} / \mathrm{cm}^{4} / \mathrm{s}$ respectively. While at $1000{ }^{\circ} \mathrm{C}$ the $\mathrm{k}_{\mathrm{p}}$ values for the same alloys are $3.35 \times 10^{-7}$ and $2.16 \times 10^{-7} \mathrm{~g}^{2} / \mathrm{cm}^{4} / \mathrm{s}$ respectively. It is obvious that oxidation kinetic is less affected when the aluminum content is low. The oxidation tendency in these low aluminum content cast irons increases with temperature. The reason for voids and cracks formation may be attributed to differential contraction of the oxide scale and metal during thermal cycling. The oxide formation along the graphite flakes and penetration of gases to cast iron can cause increase in volume which promotes voids and cracks formation.

\section{Conclusions}

1)The changeable graphitization potential of aluminum in cast iron results in producing aluminum alloyed cast irons with different and various properties.

2) Aluminum has a significant role in altering microstructure condition. Matrix structure contains various proportions of ferrite, pearlite and graphite.

3) For aluminum alloyed cast irons there is no indication of spall at temperature range between 700 and $800{ }^{\circ} \mathrm{C}$. Oxidation rate of aluminum alloyed cast iron tends to decrease with increasing aluminum content.

\section{References}

Chevalier1, S., Houngninou1, C., Paris, S., Bernard1, F., Gaffet, E., Munir, Z. A., Larpin, J. P. and Borchardt, G. (2003). Oxidation study of alumina-forming alloys, The Journal of Corrosion Science and Engineering, Vol. 6 paper H070, [on line] Available http://www.jcse.org.viewpreprint.php?vol=6 \&pap=104.

G54-84, Simple static oxidation testing, 1988 Annual Book of ASTM Standards.

Hardwick, D. and Wallwork, G. (1978). Iron-aluminum base alloys, A review of their feasibility as high temperature materials., Review of High Temperature Material, Vol. 4, 1978.

Kiani Rashid, A. R. and Edmonds, D.V. (2003). Oxydation behaviour of Al-alloyed ductile cast irons at elevated temperature. Surface and Interface Analysi. , 36, 1011-1013.

Li, D., Perrin, R., Burger, G., McFarlan, D., Black, B., Logan, R. and Williams, R. (2004). Solidification behavior, microstructure, mechanical properties, hot oxidation and thermal fatigue resistance of high silicon SiMo nodular cast irons. In Advances in lightweight automotive castings and wrought aluminum alloys (SP-1838). (2004). SAE World Congress, Detroit, Michigan March 8-11, 2004, pp. 1-12.

Nicholls, J. R. and Bennett, M. J. (2000). Cyclic oxidation-guideline for test standardization, aimed at the assessment of service behavior. Materials at High Temperatures, 17, 413-428.

Pint, B. A., Tortorelli, P. F. and Wright, I. G. (1999). Effect of cycle frequency on high temperature oxidation behavior of alumina- and chromia-Forming alloys. in M. Schütze and W. J. Quadakkers (Eds.), Cyclic oxidation of high temperature materials, The Institute of Materials, London, pp. 111-32.

Rana, A. M., Khan, A. Amjad, and T. Abbas, T. (2001). Journal of Research (Science), Bahauddin Zakariya University, Multan, Pakistan, 12, 65-71.

Sun, B. M. Z. and Wang, Z.F. (1996). Development and application of Cr-Al heat-resistant alloys cast irons. Foundry (China), 7, 31-34.

Smickley, R. J. and Rundman,K. B. (1981). The effect of aluminum on the structure and properties of gray cast iron Transaction of the American Foundrymens Society, 89, 205-214.

$\mathrm{Xu}, \mathrm{W} .$, Ferry, M., and Wang, Y. (2005). Influence of alloying elements on as-cast microstructure and strength of gray iron, Materials Science and Engineering, A 390, 326-333. 
Table 1. Chemical composition of aluminum cast irons ( $w \mathrm{t} \%)$

\begin{tabular}{|c|c|c|c|c|c|c|c|c|}
\hline $\begin{array}{c}\text { Sample } \\
\text { No. }\end{array}$ & \multicolumn{9}{|c|}{ Chemical Composition } \\
\hline I & Al & \multicolumn{1}{c|}{$\mathrm{C}$} & $\mathrm{Si}$ & $\mathrm{S}$ & $\mathrm{P}$ & $\mathrm{Mn}$ & $\mathrm{Ni}$ & $\mathrm{Cr}$ \\
\hline II & 2.0 & 3.23 & 2.1 & 0.05 & 0.09 & 0.38 & 0.05 & 0.41 \\
\hline III & 4.0 & 3.02 & 1.79 & 0.04 & 0.07 & 0.37 & 0.06 & 0.55 \\
\hline
\end{tabular}
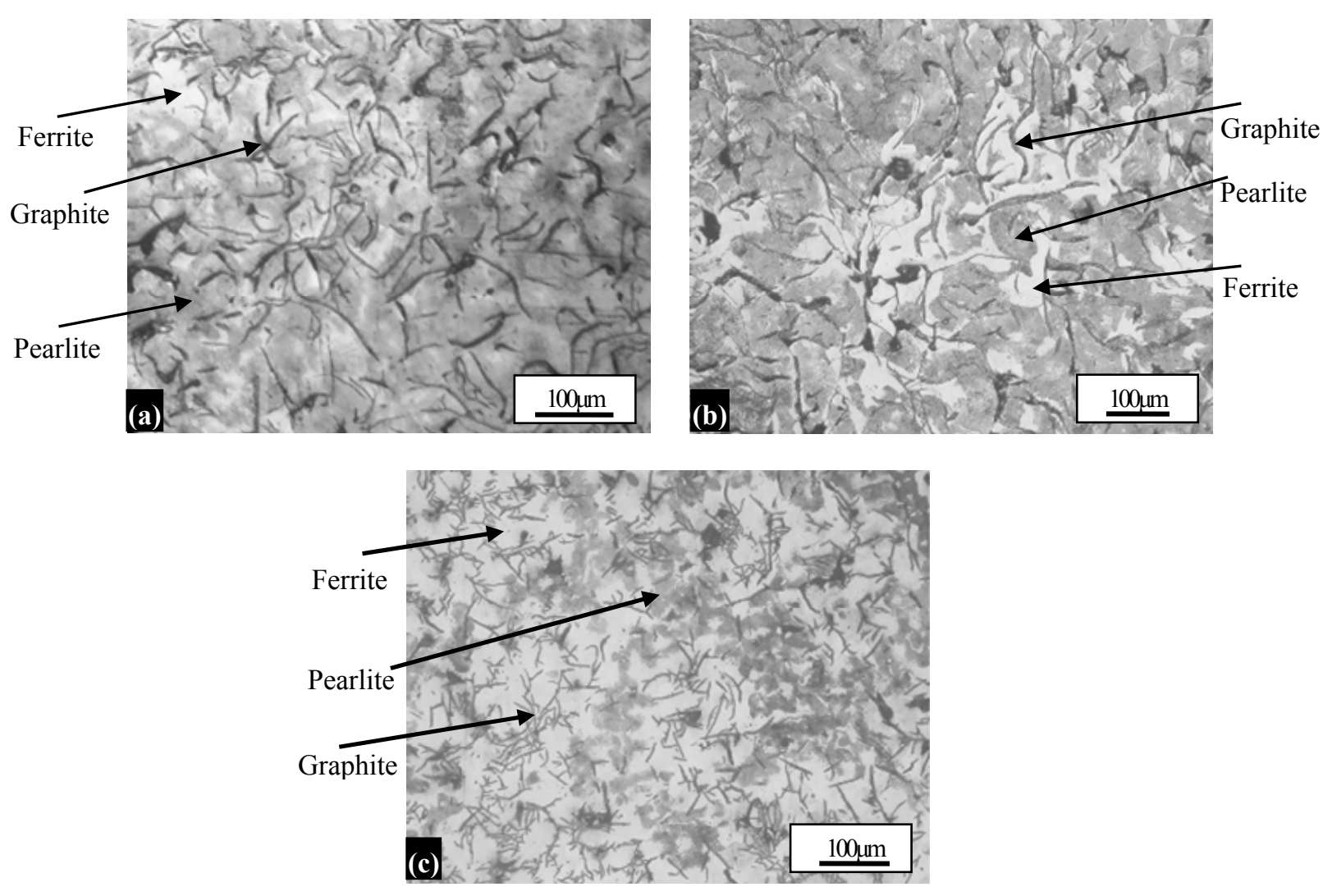

Figure 1. Microstructure of alloyed cast irons with different amounts of $\mathrm{Al}$ (a) without alminium, (b) $2.7 \%$ and (c) $4 \%$.

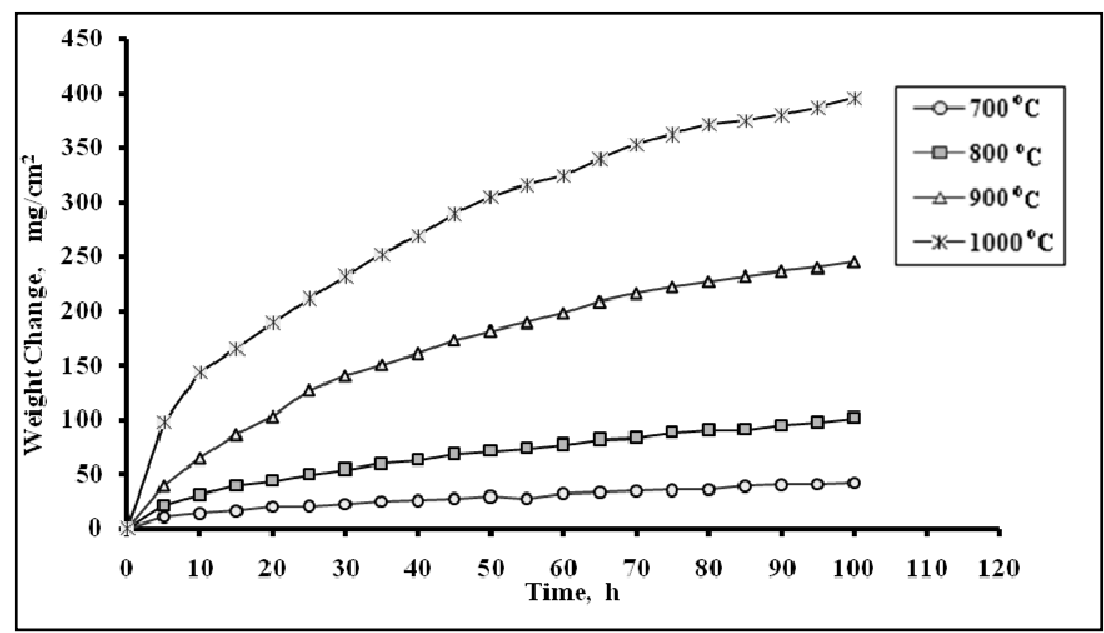

Figure 2. Weight change for aluminum free cast iron (Alloy I) oxidized in air at temperatures $700-1000{ }^{\circ} \mathrm{C}$. 

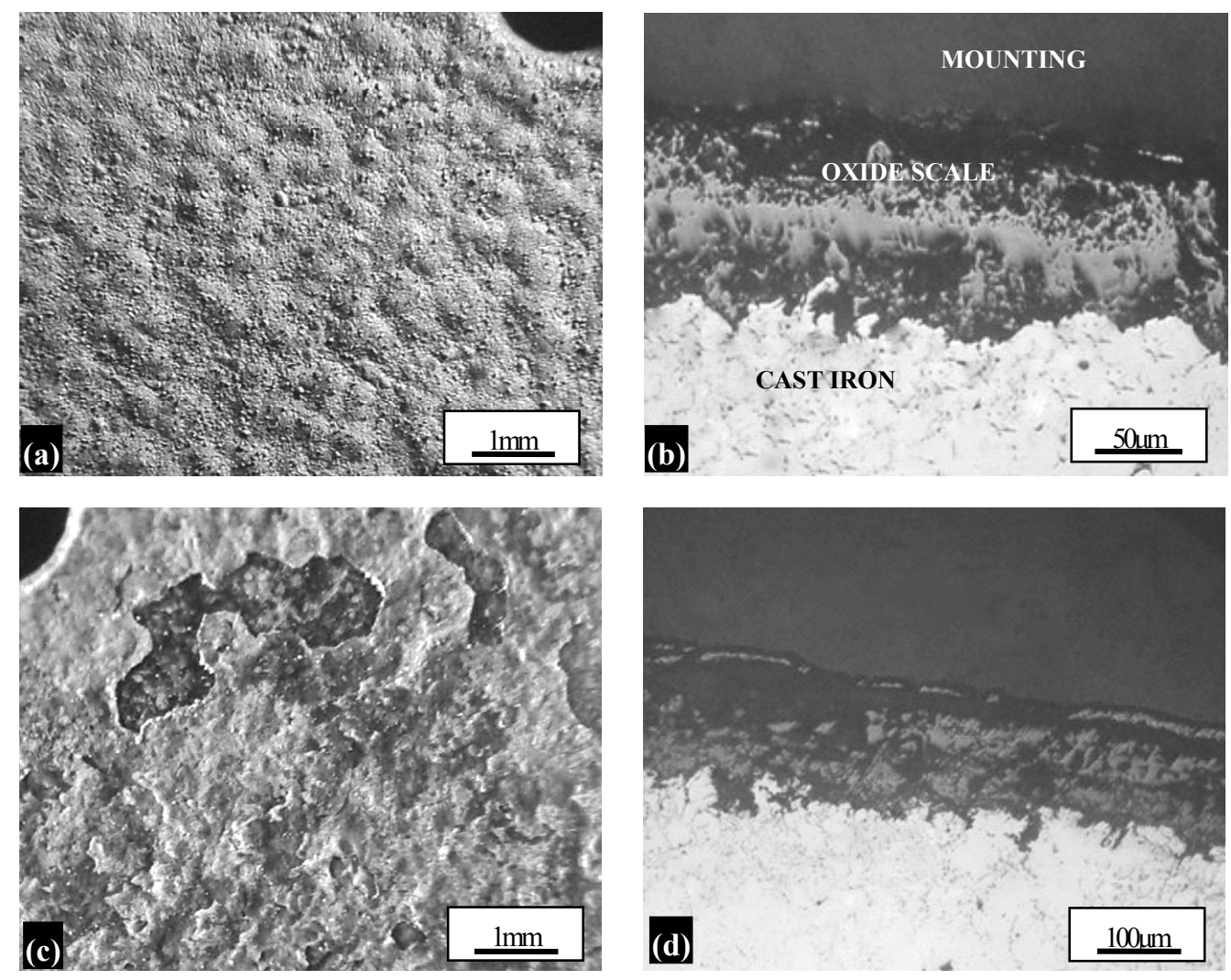

Figure 3. Surface appearance and cross section images of cast Irons (Alloy I) oxidized in air for a period of $100 \mathrm{~h}$ at $5 \mathrm{~h}$ cycle (a) and (b) $700{ }^{\circ} \mathrm{C}$, (c) and (d) $800{ }^{\circ} \mathrm{C}$.

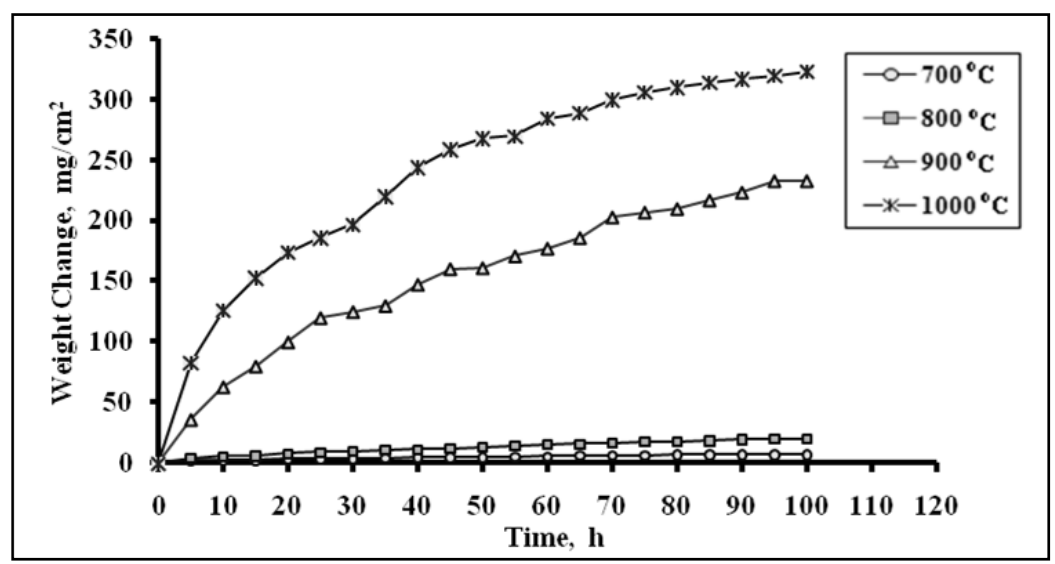

Figure 4 . Weight change for cast iron with $2.7 \%$ aluminum (alloy II) oxidized in air at temperatures $700-1000{ }^{\circ} \mathrm{C}$. 


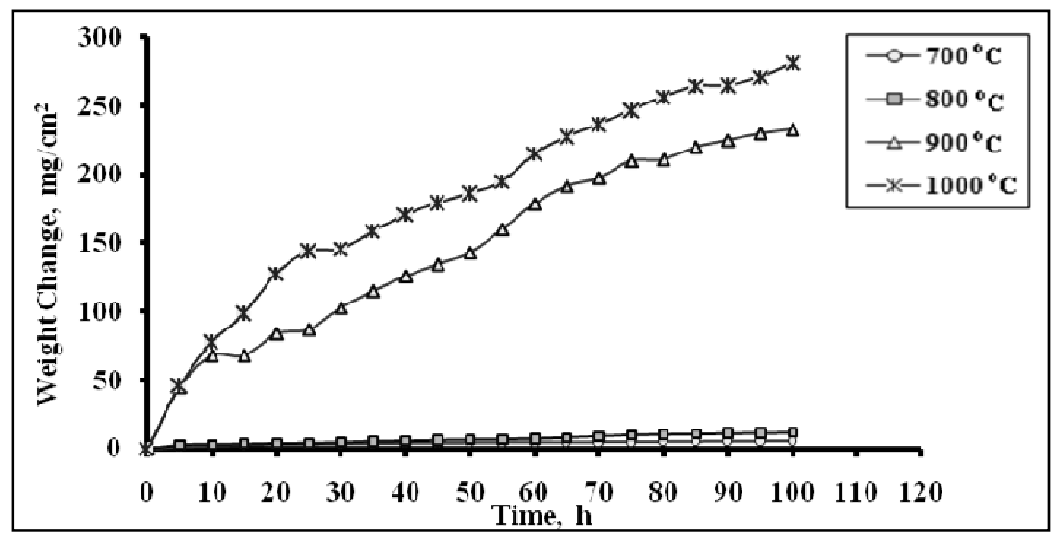

Figure 5. Weight change for cast iron alloyed with $4.0 \% \mathrm{Al}$ (Alloy III) oxidized in air at temperatures $700-1000{ }^{\circ} \mathrm{C}$.
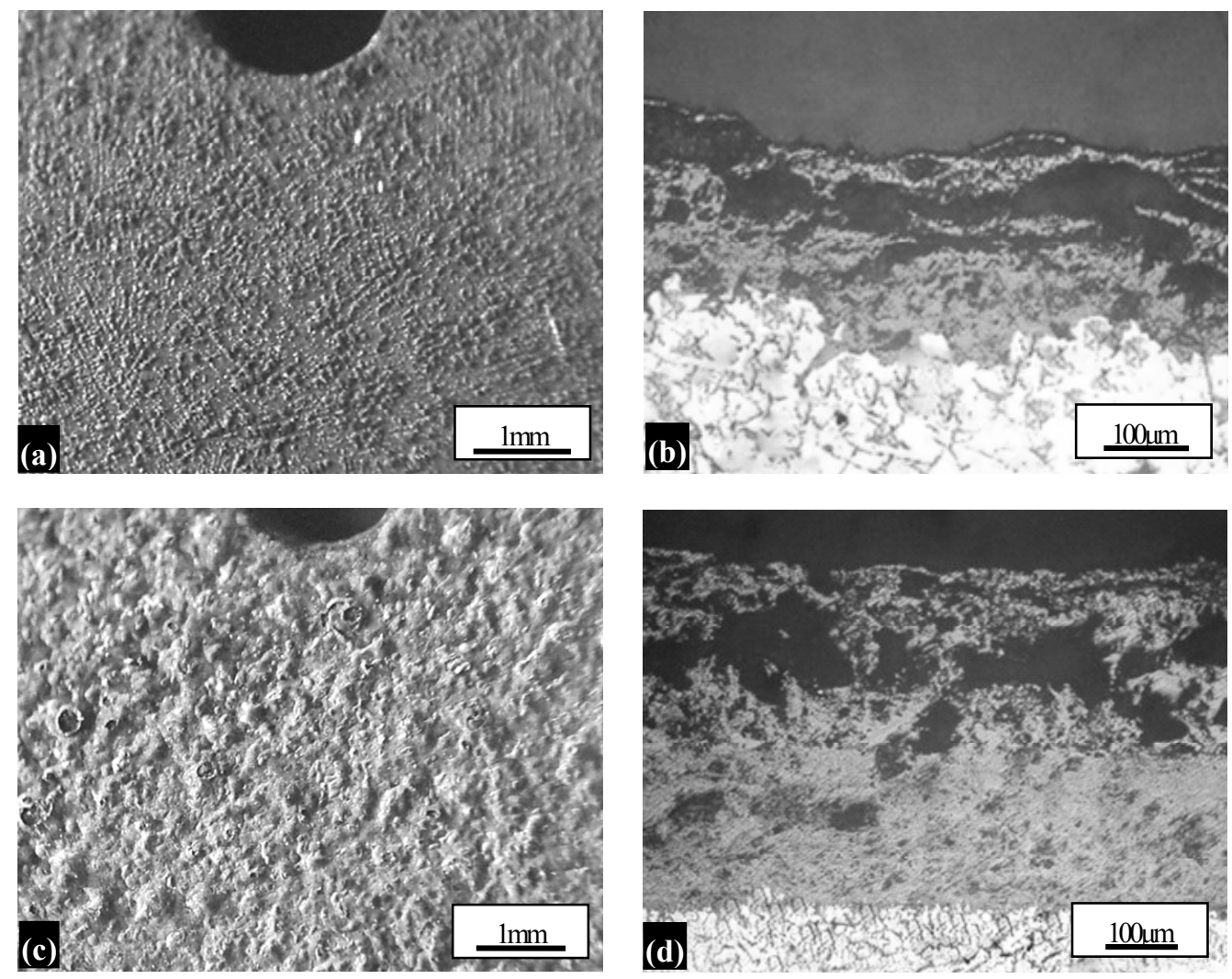

Figure 6. Surface appearance and cross section images of cast Iron (Alloy II) oxidized in air for a period of $5 \mathrm{~h} \mathrm{(a)} \mathrm{and} \mathrm{(b)} 800{ }^{\circ} \mathrm{C}$, and (c) and (d) $900{ }^{\circ} \mathrm{C}$. 